\title{
BIOCHEMICAL ANALYSIS FOR NEUROPROTECTIVE EFFECTS OF GANODERMA LUCIDUM IN EXPERIMENTAL RAT SPINAL CORD TRAUMA MODEL
}

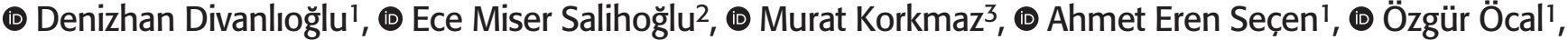 \\ (1) Göksal Günerhan', (1) Deniz Belen'1, (1) Sevgi Akaydın², (1) Ali Dalgıç
}

\author{
${ }^{1}$ Turkish Ministry of Health, Ankara City Hospital, Clinic of Neurosurgery, Ankara, Turkey \\ ${ }^{2}$ Gazi University Faculty of Pharmacy, Department of Biochemistry, Ankara, Turkey \\ ${ }^{3}$ Bakırçay University, Çiğli Training and Research Hospital, Clinic of Neurosurgery, Izmir, Turkey
}

\begin{abstract}
Objective: Injury of the spinal cord is studied in two separate mechanisms as primary and secondary injuries. During the secondary injury, spinal cord damage and related neurological defects could increase mostly because of oxidative damage. Treatments targeting this process are promising for reducing neuronal damage. Ganoderma lucidum $(\mathrm{GL})$ has the potential to suppress the inflammatory response and oxidative stress. The aim of this study is to determine the neuroprotective effect of traditional GL hot-water extract during the secondary spinal cord injury (SCI) period on an experimental rat spinal trauma model by measuring the biochemical parameters.

Materials and Methods: A total of 34 rats were distributed randomly into 4 groups as trauma, vehicle, low-dose medication group (low-DMG) and high-dose medication group (high-DMG). A modified Walsh-Tator clip was applied extradurally to form an experimental SCI model. GL liquid extract was performed in medication groups with low and high (10 times higher) oral doses. Spinal cord specimens were collected after 5 days of treatment for biochemical analysis.

Results: In the low-DMG, both diphenypicrylhydrasyl (DPPH) and malondialdehyde (MDA) values were found statistically negligible when compared with the trauma group. Comparison of the Low-DMG and vehicle group showed a significant change in DPPH value, but an insignificant change in MDA value. A statistically significant positive change in both DPPH and MDA values was found in High-DMG when compared to trauma and vehicle groups.

Conclusion: Prevention of secondary SCl is very important, since the neurological condition of the patients may get worse during this period. Dose-dependent positive results were obtained in the favor of GL in terms of both antioxidant efficacy and prevention of lipid peroxidation after $\mathrm{SCl}$. The results of this biochemical study is supporting the previous studies and showing that $\mathrm{GL}$ has the potential of reducing posttraumatic oxidative damage in the spinal cord when given at the appropriate dose.

Keywords: Ganoderma lucidum, spinal injury, rat model, oxidative damage, neuroprotection
\end{abstract}

\section{INTRODUCTION}

Spinal cord injuries ( $\mathrm{SCls}$ ), which may cause permanent disabilities, have special importance for both prevention and treatment. Injury of the spinal cord could be studied in two separate mechanisms as primary and secondary injuries. The mechanical injury that occurred right in the time of spinal trauma is named as primary injury ${ }^{(1,2)}$. Injury by the hemodynamic, metabolic, biochemical and apoptotic mechanisms initialized after hours or days following the trauma is called secondary injury ${ }^{(1,3-5)}$. In most cases, spinal cord damage and related neurological defects increase during the secondary injury period ${ }^{(6,7)}$. Treatments targeting this inflammation process are promising to attenuate neuronal damage.

There are lots of theories on the development of secondary SCI such as neurogenic shock, excitotoxicity, electrolyte imbalance, inflammation, immunological injury, vascular injury, increased intracellular calcium, free-radical development, endogenous opioids and apoptosis(5,8). Oxidative stress and inflammation are two subjects considered to be very important for secondary $\mathrm{SCl}$ development $\mathrm{t}^{(9)}$. The lipid peroxidation process is known to be the main reason for the cell membrane degradation leading to irreversible neuronal injury ${ }^{(10,11)}$. Peroxidation of fatty acids reveals an intermediate product called malondialdehyde (MDA) which can be used for measuring the level of lipid

Address for Correspondence: Denizhan Divanlıoğlu, Turkish Ministry of Health, Ankara City Hospital, Clinic of Neurosurgery, Ankara, Turkey Phone: +90 5054670299 E-mail: ddivanlioglu@gmail.com Received: 28.05.2021 Accepted: 12.07.2021

ORCID ID: orcid.org/0000-0003-0267-196X 
peroxidation $^{(10)}$. Although MDA is not a specific or quantitative indicator, it correlates with lipid peroxidation levels and could be measured by using thiobarbituric acid as applied in this study ${ }^{(10,12)}$

Ganoderma lucidum (GL) is one of the well-known mushrooms, named "Red Reishi" or "Lingzhi", which was being used for over 2000 years especially in far eastern countries because of the belief that the mushroom provides long and healthy life for the user ${ }^{(13,14)}$. This belief was supported by many scientific studies identifying active ingredients of GL such as bioactive triterpenes, polysaccharides and immunomodulatory proteins which have potent anti-tumor, anti-inflammatory and cytotoxic effects for malignant cells ${ }^{(15-18)}$. Besides, GL has the potential to suppress the inflammatory response and oxidative stress with its antioxidant, immunomodulatory and steroid-like bioactive ingredients.

The aim of this study is to investigate the neuroprotective potency of traditionally used hot-water extract of GL and if any, its' dose-dependent effects on oxidative stress by measuring the biochemical parameters, during the secondary $\mathrm{SCl}$ period.

\section{MATERIALS AND METHODS}

After ethical committee approval (2011-123-485/26.10.2011) from Ankara University Ethical Committee of Animal Experiments was taken, the experimental study and animal care were carried out at the Animal Experiments Laboratory of Ankara Hospital. Biochemical study was performed at the Pharmacology Department Laboratory of Gazi University. GL 30\% extract was obtained from Erkel Food Industry and Trade Ltd., which was produced with the authorization of The Republic of Turkey Ministry of Food, Agriculture and Livestock (food production authorization no: G34-6054-00002-4). All the subjects were obtained from Saki Yenilli Laboratory of Experimental Animal Production as 240 - 260 grams weighted, male, Wistar-Albino rats.

\section{Experiment and Surgical Procedure}

Daily care was given to a total of 34 rats in a suitable standard environment at room temperature without any food or water restrictions. The subjects were distributed randomly into 4 groups as follows:

Group 1: Trauma group $(\mathbf{n}=\mathbf{8})$ : Only spinal trauma was applied to the subjects in this group. No additional treatment was given other than standard care.

Group 2: Vehicle group $(n=8)$ : Subjects in this group were given $1 \mathrm{~mL}$ of distilled water in addition to standard care.

Group 3: Low-dose medication group (Low-DMG, n=9): The recommended daily human dose of GL hot-water extract was administered to the subject of this group in proportion of their body surface areas ${ }^{(19-21)}$.

Group 4: High-dose medication group (High-DMG, n=9): A ten times more of the recommended daily human dose of GL hotwater extract was administered to the subject of this group in proportion of their body surface areas ${ }^{(19-21)}$.
Under veterinary supervision, all the subjects were abstained from oral intake 6 hours before the anesthesia process. According to their previously calculated body surface areas, $2 \%$ xylazine hydrochloride $(10 \mathrm{mg} / \mathrm{kg})$ and $5 \%$ ketamine hydrochloride (50 mg/kg) were applied by intraperitoneal injection ${ }^{(21)}$. After appropriate surgical disinfection microsurgical procedure was started in the prone position with an interscapular midline incision. Bilateral subperiosteal blunt dissection and retraction of paravertebral muscles were followed by 3 adjacent thoracic laminectomies under extreme care for avoiding dura mater and SCl (Figure 1). A modified Walsh-Tator clip with 35 grams of closing pressure was extradurally applied for 60 seconds to all cases to form an experimental $\mathrm{SCl}$ as described by Rivlin and Tator $^{(22)}$. A line-shaped bruising over the spinal dura mater was observed in all subjects before primary closure (Figure 1 ). After the surgical procedure, all the subjects were observed as paraplegic as expected. Two hours after recovery, besides standard care without food or water restrictions, $1 \mathrm{~mL}$ of $\mathrm{GL}$ hot-water liquid extract in distilled water was started to both medication groups by orogastric cannula in two equal doses a day. Although a standardized dosage for GL hot-water extract is absent, the suggested effective dose for human usage is 1.5 $\mathrm{g}$ to $9 \mathrm{~g}$ daily for different ailments, which can be divided into 2 or 3 doses $^{(19,20)}$. Recommended mean oral dose for human daily usage was proportioned to body surface area of the subjects as $13.3 \mathrm{mg} / \mathrm{m}^{2} /$ day $(0,3 \%)$ for low-DMG and ten times more of the recommended dose, $133 \mathrm{mg} / \mathrm{m}^{2} /$ day (3\%) for high-DMG(19,20,23) Unlike the trauma group, an additional $1 \mathrm{~mL}$ of distilled water was given to the vehicle group besides standard care. No adverse effects were observed due to GL treatment.

All subjects remained paraplegic without any observable neurologic improvement during the study before, the spinal cord specimens were collected after 5 days of postoperative follow-up. The procedure was started under general anesthesia with a thoracotomy and left cardiac ventricle catheterization and followed by injection of $25 \mathrm{~mL} 0.1 \mathrm{M}$ phosphate-buffered saline solution to clean the spinal cord specimens from blood elements. After cardiac arrest developed, previous surgical incisions were reopened. For each subject, a total of $2 \mathrm{~cm}$ spinal cord segment, centering the previously injured region was harvested and the specimens were immediately stored at $-80^{\circ} \mathrm{C}$ without any contaminants.

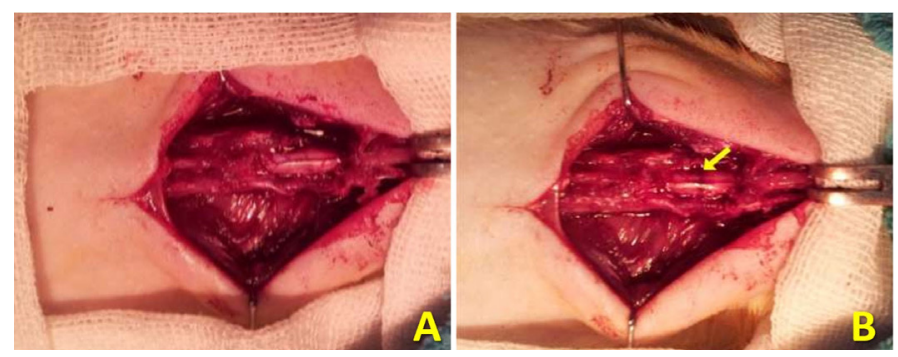

Figure 1. Spinal cord dissection after laminectomy procedure (A) and extradural marking (arrow) of spinal cord injury created with clip compression (B) 


\section{Biochemical Study}

A ten times diluted solution of $0.01 \mathrm{M}$ isotonic phosphate buffer at pH: 7.4 was prepared ( $9 \mathrm{gr} \mathrm{NaCl}, 2,575$ gr Na${ }_{2} \mathrm{HPO}_{4} .7 \mathrm{H}_{2} \mathrm{O}$, $0.274 \mathrm{gr} \mathrm{NaH} \mathrm{PO}_{4} \cdot 2 \mathrm{H}_{2} \mathrm{O}$, distilled water). Spinal cord samples were weighed and $10 \mu \mathrm{L}$ of the buffer solution per sample weight in milligrams were added. Weights of the collected spinal cord samples were given in Table 1. Prepared samples were homogenized twice under ice-cooling using Ultra Turnax ${ }^{\circledast}$ T18 Basic Homogenizer at 14.000rpm for 30 seconds. The homogenates were centrifuged at $17,000 \mathrm{~g},+4^{\circ} \mathrm{C}$ for 20 minutes, and $250 \mu \mathrm{L}$ of the supernatants were separated for the biochemical study.

The samples were hydrolyzed in a $50 \mu \mathrm{L} \mathrm{NaOH}$ solution at $60^{\circ}$ $\mathrm{C}$ for 30 minutes using an incubator and acidified by using 125 $\mu \mathrm{L}$ perchloric acid solution. After re-centrifugation at 14,000 $g$ for 10 minutes, $250 \mu \mathrm{L}$ of supernatants were separated in glass tubes. Then the samples were incubated with $25 \mu \mathrm{L}$ 2.4-dinitrophenylhydrazine for 10 minutes and twice extraction with hexane was performed before the organic phases were dried at $-40^{\circ} \mathrm{C}$ using nitrogen ${ }^{(24-26)}$.

For total MDA quantity measurement, $20 \mu \mathrm{L}$ of each sample was studied with $310 \mathrm{~nm}$ wavelength using high performance liquid chromatography (HPLC) at $30^{\circ} \mathrm{C}$ with a flow rate of $0.6 \mathrm{~mL} / \mathrm{min}^{(26)}$. For antioxidant capacity determination 1.2 mg 2.2-diphenyl-1-picrylhydrasyl (DPPH) and $50 \mathrm{~mL} \mathrm{MetOH}$ radical solutions were used. For $10 \mu \mathrm{L}$ of each sample a 20 $\mu \mathrm{L}$ of $\mathrm{MetOH}$ was added on and the obtained solution was centrifuged at $15,000 \mathrm{~g}$ for 20 minutes. Obtained supernatant $(15 \mu \mathrm{L})$ was mixed with DPPH solution $(195 \mu \mathrm{L})$ and incubated for 30 minutes in total darkness. Then the samples and DPPH radical solution were studied for absorbance values at $515 \mathrm{~nm}$ wavelength using HPLC. Inhibition \% values were calculated using "Inhibition \%= $A_{D P P H}-A_{\text {sample }} / A_{D P P H} \times 100$ " formula ${ }^{(24,25)}$.

\section{Statistical Analysis}

Obtained data from HPLC wavelength peak areas representing MDA levels and absorbance inhibition levels of the DPPH treated samples were calculated using the Statistical Package for the Social Sciences (SPSS v16.0.0) software. A Levene's test was used for the evaluation of homogeneity of variances and the study groups were compared with the independent samples t-test, including mean and standard deviations in \%95 confidence intervals. P-value $\leqslant 0.05$ was considered as statistically significant and group comparisons were summarized in Table 2.

\section{RESULTS}

DPPH levels: For the Low-DMG, differences in DPPH levels were found statistically negligible when compared with the trauma group ( $p>0.05)$. Low-DMG and vehicle groups comparison showed a significant DPPH difference $(p \leqslant 0.05)$. High-DMG showed an evident statistically significant difference compared to the trauma group for the DPPH levels $(p \leqslant 0,05)$. High-DMG and vehicle group comparisons were also significant for DPPH levels $(p \leqslant 0.05)$. Comparisons for DPPH levels of High-DMG and Low-DMG showed an insignificant difference ( $p>0.05)$.

MDA levels: Comparison of Low-DMG and trauma groups were insignificant for MDA values ( $p>0.05)$. Low-DMG and vehicle groups comparison was also insignificant for MDA ( $p>0.05)$ values. For high-DMG, differences in MDA levels were found statistically significant when compared to the trauma group $(p \leqslant 0.05)$. High-DMG and vehicle group comparisons were also significant for MDA values ( $p \leqslant 0.05)$. Comparisons for MDA levels of high-DMG and low-DMG showed an insignificant difference $(p>0.05)$.

\section{DISCUSSION}

SCls have special importance for both prevention and treatment especially for causing personal and social health problems. Most of the patients suffer from permanent incapacities, severe labor loss, and high expenses for hospitalization followed by long-term rehabilitation programs. Preventing the primary spinal injury is golden for sure but, the patients are always at the secondary $\mathrm{SCl}$ period at the time of hospital admission. Relatively fortunate patients with incomplete $\mathrm{SCl}$ on hospital admission frequently get worse over hours or days during the

Table 1. Weights of the collected spinal cord samples in miligrams

\begin{tabular}{lllll}
\hline Sample & High-DMG & Low-DMG & Vehicle Group & Trauma Group \\
\hline $\mathbf{1}$ & 174.0 & 221.7 & 156.5 & 190.4 \\
\hline $\mathbf{2}$ & 95.6 & 114.4 & 196.8 & 314.6 \\
\hline $\mathbf{3}$ & 161.8 & 180.0 & 154.3 & 209.7 \\
\hline $\mathbf{4}$ & 188.8 & 167.0 & 205.0 & 141.3 \\
\hline $\mathbf{5}$ & 230.2 & 204.7 & 152.6 & 140.3 \\
\hline $\mathbf{6}$ & 232.9 & 209.6 & 209.4 & 138.0 \\
\hline $\mathbf{8}$ & 151.9 & 248.8 & 63.5 & 168.4 \\
\hline $\mathbf{9}$ & 201.2 & 115.0 & 225.6 & 202.0 \\
\hline Mean & 154.3 & 134.6 & - & - \\
\hline
\end{tabular}

DMG: Dose medication group 
Table 2. Statistical comparisons of the experiment groups

\begin{tabular}{|c|c|c|c|c|c|c|}
\hline & Groups & $\mathbf{N}$ & Mean & $\begin{array}{l}\text { Standard } \\
\text { Deviation }\end{array}$ & $\begin{array}{l}\text { Standard Error } \\
\text { Mean }\end{array}$ & Sig. \\
\hline \multirow{2}{*}{ DPPH } & Low-DMG & 9 & 10.5509 & 2.84696 & 0.94899 & \multirow{2}{*}{$p>0.05$} \\
\hline & Trauma & 8 & 11.2185 & 5.57615 & 1.97147 & \\
\hline \multirow{2}{*}{ MDA } & Low-DMG & 9 & 4.8560 & 1.33605 & 0.44535 & \multirow{2}{*}{$p>0.05$} \\
\hline & Trauma & 8 & 2.8867 & 1.09488 & 0.38710 & \\
\hline \multirow{2}{*}{ DPPH } & Low-DMG & 9 & 10.5509 & 2.84696 & 0.94899 & \multirow{2}{*}{$p \leqslant 0.05$} \\
\hline & Vehicle & 8 & 13.6134 & 7.12992 & 2.52081 & \\
\hline \multirow{2}{*}{ MDA } & Low-DMG & 9 & 4.8560 & 1.33605 & 0.44535 & \multirow{2}{*}{$p>0.05$} \\
\hline & Vehicle & 8 & 3.8158 & 1.52369 & 0.53871 & \\
\hline \multirow{2}{*}{ DPPH } & High-DMG & 9 & 13.4827 & 2.31020 & 0.77007 & \multirow{2}{*}{$p \leqslant 0.05$} \\
\hline & Trauma & 8 & 11.2185 & 5.57615 & 1.97147 & \\
\hline \multirow{2}{*}{ MDA } & High-DMG & 9 & 2.6651 & 0.57380 & 0.19127 & \multirow{2}{*}{$p \leqslant 0.05$} \\
\hline & Trauma & 8 & 2.8867 & 1.09488 & 0.38710 & \\
\hline \multirow{2}{*}{ DPPH } & High-DMG & 9 & 13.4827 & 2.31020 & 0.77007 & \multirow{2}{*}{$p \leqslant 0.05$} \\
\hline & Vehicle & 8 & 13.6134 & 7.12992 & 2.52081 & \\
\hline \multirow{2}{*}{ MDA } & High-DMG & 9 & 2.6651 & 0.57380 & 0.19127 & \multirow{2}{*}{$p \leqslant 0.05$} \\
\hline & Vehicle & 8 & 3.8158 & 1.52369 & 0.53871 & \\
\hline \multirow{2}{*}{ DPPH } & High-DMG & 9 & 13.4827 & 2.31020 & 0.77007 & \multirow{2}{*}{$p>0.05$} \\
\hline & Low-DMG & 9 & 10.5509 & 2.84696 & 0.94899 & \\
\hline \multirow{2}{*}{ MDA } & High-DMG & 9 & 2.6651 & 0.57380 & 0.19127 & \multirow{2}{*}{$p>0.05$} \\
\hline & Low-DMG & 9 & 4.8560 & 1.33605 & 0.44535 & \\
\hline
\end{tabular}

DPPH: Diphenypicrylhydrasyl, MDA: Malondialdehyde, DMG: Dose medication group

secondary injury period which makes the treatment of secondary injury so important ${ }^{(1,3,5,7,7,16,27)}$. Besides lots of factors that were accused for the development of secondary $\mathrm{SCl}$, it is known that oxidative stress has a significant role in this mechanism, which makes it a good target for new treatment modalities ${ }^{(9)}$. This is the main reason that this study was focused on oxidative injury mechanisms.

There are many experimental spinal trauma models developed so far. One of these standardized methods is the clipcompression method described by Rivlin and Tator ${ }^{(28)}$. In this study, this clip-compression method was preferred because of its high reliability and similitude according to human spinal injuries ${ }^{(22,28,29)}$. By this method, ischemia and neuroinflammation related free oxygen radical formation and lipid peroxidation can be created. During and after the application of clip compression, a perfusion defect occurs in all circulatory levels (arteriolar, venular and capillary) similar to the changes that occur during human spinal traumas ${ }^{(1,30)}$.

Although GL was being used traditionally for thousands of years especially in the far eastern countries, it was recognized and began to be researched in western medicine in the 1980s. These studies revealed a variety of biological activities for this mushroom such as anti-neoplastic, anti-inflammatory, immunomodulatory, immunotherapeutic, hepatoprotective and ACE inhibitory effects ${ }^{(31-37)}$. Pharmacologically active ingredients of $\mathrm{GL}$ are triterpenes, which have similar molecular structures like steroid hormones and polysaccharides (especially $\beta$-dglucan). These pharmacologically active molecules were recognized both in vitro and in vivo studies for preventing free oxygen radical generation and reducing their cellular oxidative damage ${ }^{(32,36,38)}$. This antioxidant effect is highest in Terpenes such as ganoderic acid A, B, C and D, lucidenic acid B and ganodermanontriol ${ }^{(36)}$. At the same time, it was shown that the "GL peptide" can effectively eradicate hydroxyl and superoxide radicals dose-dependently ${ }^{(39)}$. Shi et al. ${ }^{(40)}$ studied hot water extracts of eight different mushrooms for their potential of reducing hydrogen peroxide $\left(\mathrm{H}_{2} \mathrm{O}_{2}\right)$ mediated oxidative stress and found that $\mathrm{GL}$ has a high antioxidant feature and it has the potential to protect cellular DNA from oxidative damage. In a following in vitro study by Abdullah et al. ${ }^{(41)}$, an antioxidant index (Al) was generated for hot water extracts of different mushroom species and $\mathrm{GL}\left(\mathrm{IC}_{50}=50 \mu \mathrm{g} / \mathrm{mL}\right)$ was found to be the most potent with a $30.1 \% \mathrm{Al}$.

There are various studies showing that GL treatment reduces oxidative damage both in vitro and in vivo ${ }^{(42-44)}$. These findings were also similar in the central nervous system, especially studied on cerebral oxidative injury models ${ }^{(45,46)}$, and previous spinal trauma models. In a detailed clip-compression spinal trauma experiment on rats, pre-isolated GL polysaccharides (GLPS) were administered before $\mathrm{SCl}$. This biochemical, histopathological and ultrastructural study by Gokce et al. ${ }^{(47)}$, showed positive results on reducing oxidative damage in favor 
of crude GLPS. In another detailed study by Kahveci et al.(48), ischemia-reperfusion injury was created in the spinal cord by clamping the aorta, and pre-isolated GLPS were given to the subjects before $\mathrm{SCl}$. Successful results were obtained with GLPS in preventing oxidative damage ${ }^{(48)}$. In a weight-dropping spinal cord injury rat model by Ekinci et al.(49), isolated GLPS were used after $\mathrm{SCl}$. Biochemical and histopathological evaluations showed that, the use of GLPS had positive results in preventing oxidative damage ${ }^{(49)}$. In all three $\mathrm{SCl}$ studies mentioned above, subjects were administered pre-isolated GLPS at a constant dose of $400 \mathrm{mg} / \mathrm{kg} /$ day. In the first two studies, GLPS treatment was started 7 days before the $\mathrm{SCl}$ and spinal cord tissues were obtained 24 hours after the injury. In the last study mentioned, GLPS treatment was applied for 7 days after SCI. As mentioned before, polysaccharides, triterpenoids and peptides in $\mathrm{GL}$ were also determined to be bioactive. Therefore, in our study, unlike these studies, traditionally consumed hot-water extract of GL was tested at different doses without pre-isolating GLPS. In daily practice, since the treatment of spinal cord injuries is usually started after the injury, it was preferred to start the $\mathrm{GL}$ application after the $\mathrm{SCl}$ was created in the experiment. In previous biochemical experiments, the levels of different tissue free oxygen radicals and antioxidants were measured and the positive effects of the use of GL were shown ${ }^{(47-49)}$. In our study, in addition to the MDA level measurement used for the evaluation of lipid peroxidation, the antioxidant capacity of spinal cord tissue after $\mathrm{SCl}$ was tried to be tested by measuring the DPPH level.

To the subjects in low-DMG, the average recommended GL hotwater extract dose for humans was applied, in proportion to the rats, while ten times more dose was applied to the subjects in high-DMG ${ }^{(19,20)}$. In this study, supporting the previous studies, it was found that the $\mathrm{GL}$ treatment after $\mathrm{SCl}$, increases the absorbance values of the DPPH treated spinal cord samples, and decreases the MDA levels. These positive results could only be obtained in the high dose medication group when compared to the trauma and vehicle groups. It was determined that, only DPPH change is statistically significant for the comparison of the Low-DMG and the vehicle group but, it was insignificant for MDA values. In the comparison of high-DMG and low-DMG, insignificant results were found for both DPPH and MDA values. These findings suggest that $G L$ treatment also had some efficacy at low doses, but since it is not affecting MDA values, the efficacy could be considered as inconsistent and negligible. Since, traditional GL hot-water extract started in a sufficient dose range during the secondary $\mathrm{SCl}$ period prevents the oxidative damage, it was thought to have therapeutic potential for secondary SCl. Previous studies have shown that the efficacy of methylprednisolone (MP), the commonly used drug in the treatment of spinal injury, and $G L$ are similar ${ }^{(47,49)}$. However, various and sometimes serious side effects can be observed due to MP therapy ${ }^{(50)}$. There are no serious side-effects encountered previously for $\mathrm{GL}$ both in animal and human experiments ${ }^{(23,51,52)}$.
Besides its potential, the lack of significant side effect even at high doses makes $\mathrm{GL}$ more clinically valuable. The common handicap of experimental studies on this subject, including ours, is the limited number of subjects. Studies with more subjects are needed to establish a treatment protocol for human use.

\section{CONCLUSION}

In this study, the antioxidant neuroprotective effect of GL was biochemically investigated in a spinal cord injury model created by clip compression in rats. After $\mathrm{SCl}$ was administered, traditional GL hot water extract was given for 5 days to the subjects in two different dose groups and spinal cord samples were compared with control groups. Positive dose-dependent results were obtained by $\mathrm{GL}$ treatment in terms of both tissue antioxidant efficacy and prevention of lipid peroxidation. The results of the study is supporting the previous work, and showing that $\mathrm{GL}$ has the potential of reducing oxidative stress that causes secondary $\mathrm{SCl}$ when given at the appropriate dose. As a result, it was determined that GL traditional hot-water extract has a preventive effect on oxidative damage when applied in the secondary $\mathrm{SCl}$ period in a dose-dependent manner.

\section{Ethics}

Ethics Committee Approval: The study was approved by the Ankara University Ethics Committee of Animal Experiments (2011-123-485/26.10.2011).

Informed Consent: Animal study, spinal cord injury.

\section{Author Contributions}

Surgical and Medical Practices: D.D., M.K., D.B., A.D., Concept: D.D., M.K., D.B., A.D., Design: D.D., E.M.S., M.K., D.B., S.A., A.D., Data Collection or Processing: D.D., E.M.S., M.K., G.G., S.A., D.B., A.D., Analysis or Interpretation: D.D., E.M.S., A.E.S., Ö.Ö., G.G., S.A., D.B., A.D., Literature Search: D.D., E.M.S., A.E.S., Ö.Ö., G.G., D.B., A.D., Writing: D.D., A.E.S., D.B., A.D.

Financial Disclosure: The authors declared that this study received no financial support.

Conflict of Interest: The authors have no conflicts of interest to declare.

\section{REFERENCES}

1. Tator $\mathrm{CH}$, Fehlings MG. Review of the secondary injury theory of acute spinal cord trauma with emphasis on vascular mechanisms. J Neurosurg. 1991;75:15-26.

2. Fehlings MG, Sekhon $\mathrm{LH}$, Tator $\mathrm{C}$. The role and timing of decompression in acute spinal cord injury: what do we know? What should we do? Spine (Phila Pa 1976). 2001;26(Suppl 24):S101-110.

3. Hardman J. Cerebrospinal Trauma. In: Davis R, Robertson D (Eds.). Textbook of Neuropathology. Second edition, Williams and Wilkins, Baltimore 1991;pp:962-1003.

4. Crowe MI, Bresnahan IC, Shuman SL, Masters IN, Beattie MS. Apoptosis and delayed degeneration after spinal cord injury in rats and monkeys. Nat Med. 1997;3:73-6.

5. Iplikcioglu C. Omurilik yaralanmasının fizyopatolojisi. İçinde: Özer F, Zileli M (Eds.). Omurilik ve Omurga Cerrahisi. Birinci basım, Saray Medikal Yayıncılık, İzmir 2002;pp:459-65. 
6. Popovich PG, Longbrake EE. Can the immune system be harnessed to repair the CNS? Nat Rev Neurosci. 2008;9:481-93.

7. Rossignol S, Schwab M, Schwartz M, Fehlings MG. Spinal cord injury: time to move? J Neurosci. 2007;27:11782-92.

8. Tator C. Neurosurgery. In: Wilkins R, Rengachary S (Eds.). Second edition, McGraw-Hill, New York 1996;pp:2847-59.

9. Popovich PG, Jones TB. Manipulating neuroinflammatory reactions in the injured spinal cord: back to basics. Trends Pharmacol Sci. 2003;24:13-7.

10. Erden M. Serbest radikaller. Turkiye Klinikleri J Med Sci. 1992;12:201-7.

11. Sakamoto A, Ohnishi ST, Ohnishi T, Ogawa R. Relationship between free radical production and lipid peroxidation during ischemiareperfusion injury in the rat brain. Brain Res. 1991;554:186-92.

12. Valenzuela A. The biological significance of malondialdehyde determination in the assessment of tissue oxidative stress. Life Sci. 1991;48:301-9.

13. Chang ST, Buswell JA. Medicinal mushrooms-a prominent source of nutriceuticals for the 21st century. Curr Top Nutraceutical Res. 2003; 1:257-80.

14. Wachtel-Galor S, Yuen J, Buswell JA, Benzie IFF. Ganoderma lucidum (Lingzhi or Reishi): A Medicinal Mushroom. In: Benzie IFF, WachtelGalor S (Eds.). Herbal Medicine: Biomolecular and Clinical Aspects. Second edition, CRC Press/Taylor \& Francis, Boca Raton (FL) 2011.

15. Dzubak P, Hajduch M, Vydra D, Hustova A, Kvasnica M, Biedermann $D$, et al. Pharmacological activities of natural triterpenoids and their therapeutic implications. Nat Prod Rep. 2006;23:394-411.

16. Lin Z-B. Cellular and molecular mechanisms of immuno-modulation by Ganoderma lucidum. J Pharmacol Sci. 2005;99:144-53.

17. Sone Y, Okuda R, Wada N, Kishida E, Misaki A. Structures and antitumor activities of the polysaccharides Isolated from fruiting body and the growing culture of mycelium of Ganoderma lucidum. Agr Biol Chem. 1985; 49:2641-53.

18. Miyazaki T, Nishijima M. Studies on fungal polysaccharides. XXVII. Structural examination of a water-soluble, antitumor polysaccharide of Ganoderma lucidum. Chem Pharm Bull (Tokyo). 1981;29:3611-6.

19. Soo TS. Effective dosage of the extract of Ganoderma lucidum in the treatment of various ailments. In: Royse DJ, (Ed.). shroom biology and mushroom products : proceedings of the 2nd International Conference, June 9-12, 1996, University Park, Pennsylvania. 1996;pp:177-85.

20. Chang R. Effective dose of Ganoderma in humans. Taipei; 1994. p. 101-13. In: Buchanan P, Hseu R, Moncalvo J (Eds.). Proceedings of the Contributed Symposium 59A, B of the 5th International Mycological Congress. Taipei, 1994;pp:101-13.

21. Cheung MC, Spalding PB, Gutierrez JC, Balkan W, Namias N, Koniaris LG, et al. Body surface area prediction in normal, hypermuscular, and obese mice. J Surg Res. 2009;153:326-31.

22. Rivlin AS, Tator $\mathrm{CH}$. Objective clinical assessment of motor function after experimental spinal cord injury in the rat. I Neurosurg. 1977;47:577-81.

23. Li EK, Tam L-S, Wong CK, Li WC, Lam CWK, Wachtel-Galor S, et al. Safety and efficacy of Ganoderma lucidum (lingzhi) and San Miao San supplementation in patients with rheumatoid arthritis: A doubleblind, randomized, placebo-controlled pilot trial. Arthritis Rethum. 2007; 57:1143-50.

24. Bondet V, Brand-Williams W, Berset C. Kinetics and Mechanisms of Antioxidant Activity using the DPPH free radical method. LWT Food Sci Technol. 1997;30:609-15.

25. Kedare SB, Singh RP. Genesis and development of DPPH method of antioxidant assay. J Food Sci Technol. 2011;48:412-22.

26. Pilz J, Meineke I, Gleiter $\mathrm{CH}$. Measurement of free and bound malondialdehyde in plasma by high-performance liquid chromatography as the 2,4-dinitrophenylhydrazine derivative. J Chromatogr B Biomed Sci Appl. 2000;742:315-25.

27. Dumont RJ, Verma S, Okonkwo DO, Hurlbert RJ, Boulos PT, Ellegala DB, et al. Acute spinal cord injury, part II: contemporary pharmacotherapy. Clin Neuropharmacol. 2001;24:265-79.
28. Rivlin AS, Tator $\mathrm{CH}$. Regional spinal cord blood flow in rats after severe cord trauma. J Neurosurg. 1978;49:844-53.

29. Khan M, Griebel R. Acute spinal cord injury in the rat: comparison of three experimental techniques. Can J Neurol Sci. 1983;10:161-5.

30. Taoka $Y$, Okajima K. Spinal cord injury in the rat. Progress in Neurobiology. 1998;56:341-58.

31. Mizuno T, Wang G, Zhang J, Kawagishi H, Nishitoba T, Li J. Reishi, Ganoderma lucidum and Ganoderma tsugae: bioactive substances and medicinal effects. Food Rev Int. 1995;11:151-66.

32. Paterson RRM. Ganoderma - a therapeutic fungal biofactory. Phytochemistry. 2006;67:1985-2001.

33. Lindequist $U$, Niedermeyer THJ, Jülich W-D. The pharmacological potential of mushrooms. Evid Based Complement Alternat Med. 2005;2:285-99.

34. Hai-Bang T, Shimizu K. Structure-activity relationship and inhibition pattern of reishi-derived (Ganoderma lingzhi) triterpenoids against angiotensin-converting enzyme. Phytochem Lett. 2015;12:243-7.

35. Bensky D, Kaptchuk TJ. Chinese Herbal Medicine: Materia Medica. Eastland Press, Seattle, 1993;pp:556.

36. Zhu M, Chang Q, Wong LK, Chong FS, Li RC. Triterpene antioxidants from ganoderma lucidum. Phytother Res. 1999;13:529-31.

37. Suarez-Arroyo II, Rosario-Acevedo R, Aguilar-Perez A, Clemente PL, Cubano LA, Serrano J, et al. Anti-tumor effects of Ganoderma lucidum (reishi) in inflammatory breast cancer in in vivo and in vitro models. PLoS One. 2013;8:e57431.

38. Palaoglu S. Akut Omurilik Yaralanmasının Tedavisinde Iyileşmeyi Hızlandıran Farmakolojik ve Cerrahi Girişimler. Turk J Phys Med Rehabil. 2002;48. Available from: https://www.ftrdergisi.com/ abstract.php?id=3388 [Online ahead of print]

39. Sun J, He H, Xie B. Novel antioxidant peptides from fermented mushroom Ganoderma lucidum. J Agric Food Chem. 2004;52:6646-52.

40. Shi Y, James AE, Benzie IFF, Buswell JA. Mushroom-derived preparations in the prevention of $\mathrm{H} 2 \mathrm{O} 2$-induced oxidative damage to cellular DNA. Teratog Carcinog Mutagen. 2002;22:103-11.

41. Abdullah N, Ismail SM, Aminudin N, Shuib AS, Lau BF. Evaluation of selected culinary-medicinal mushrooms for Antioxidant and ACE Inhibitory activities. Evid Based Complement Alternat Med. 2012;2012:464238.

42. Lin W-C, Lin W-L. Ameliorative effect of Ganoderma lucidum on carbon tetrachloride-induced liver fibrosis in rats. World J Gastroenterol. 2006;12:265-70.

43. Sudheesh NP, Ajith TA, Mathew J, Nima N, Janardhanan KK. Ganoderma lucidum protects liver mitochondrial oxidative stress and improves the activity of electron transport chain in carbon tetrachloride intoxicated rats. Hepatol Res 2012;42:181-91.

44. You Y-H, Lin Z-B. Protective effects of Ganoderma lucidum polysaccharides peptide on injury of macrophages induced by reactive oxygen species. Acta Pharmacol Sin. 2002;23:787-91.

45. Zhou Y, Qu Z, Zeng Y, Lin Y, Li Y, Chung P, et al. Neuroprotective effect of preadministration with Ganoderma lucidum spore on rat hippocampus. Exp Toxicol Pathol. 2012;64:673-80.

46. Zhou Z-Y, Tang Y-P, Xiang J, Wua P, Jin H-M, Wang Z, et al. Neuroprotective effects of water-soluble Ganoderma lucidum polysaccharides on cerebral ischemic injury in rats. J Ethnopharmacol. 2010;131:154-64.

47. Gokce EC, Kahveci R, Atanur OM, Gürer B, Aksoy N, Gokce A, et al. Neuroprotective effects of Ganoderma lucidum polysaccharides against traumatic spinal cord injury in rats. Injury. 2015;46:2146-55.

48. Kahveci R, Kahveci FO, Gokce EC, Gokce A, Kısa Ü, Sargon MF, et al. Effects of Ganoderma lucidum polysaccharides on different pathways involved in the development of spinal cord ischemia reperfusion injury: biochemical, histopathologic, and ultrastructural analysis in a rat model. World Neurosurg. 2021;150:e287-97.

49. Ekinci A, Ozevren $H$, Bilgiç BE, Ekinci C, Deveci $S$, Deveci E. Neuroprotective effects of Ganoderma lucidum on spinal cord injury. Int J Morphol. 2018;36:175-9.Yasir M, Goyal A, Bansal P, Sonthalia 
turkishspine

S. Corticosteroid Adverse Effects. In: StatPearls [Internet]. Treasure Island (FL): StatPearls Publishing; 2021 [cited 2021 Jul 9]. Available from: http://www.ncbi.nlm.nih.gov/books/NBK531462/

50. Noguchi M, Kakuma T, Tomiyasu K, Yamada A, Itoh K, Konishi F, et al. Randomized clinical trial of an ethanol extract of Ganoderma lucidum in men with lower urinary tract symptoms. Asian J Androl. 2008; 10:777-85.
51. Kim MJ, Kim HW, Lee YS, Shim MJ, Choi EC, Kim BK. Studies on Safety of Ganoderma lucidum. The Korean Journal of Mycology. $1986 ; 14: 49-59$. 